\title{
Penalty-PSO Algorithm for Sequencing Mixed Model Assembly Line
}

\author{
Chenglong Lu, Bo Zhu *, Beibei Liu and Yuwei Wan \\ Kunming University of Science and Technology, Kunming, China \\ ${ }^{*}$ Corresponding author
}

\begin{abstract}
A mathematical model of sequencing problem which takes the minimum overload time as the optimization objective is established to solve mixed model assembly line sequencing problem in semi-closed station. A new penalty strategy that can eliminate the influence of the viscous effect which caused by the inherent defects of the reset strategy is proposed. A Penalty-PSO Algorithm based on penalty strategy has been designed for mixed model assembly line sequencing problem. Experimental results confirm the effectiveness and superiority of Penalty-PSO Algorithm in solving mixed model assembly sequencing problem.
\end{abstract}

\section{Keywords-PSO; MMALSP; Penalty Strategy}

\section{INTRODUCTION}

Compared to the traditional assembly line, mixed model assembly line(MMAL) has a significant cost advantage. The sequence of production could affect the production efficiency, therefore, the key to improve the efficiency of the mixed model assembly line is to solve the problem of the assembly line sequencing problem(MMALSP).

There has been certain amount of research into this subject, such as the traditional mathematical method and the intelligent optimization algorithm. The intelligent optimization algorithm includes genetic algorithm[1], simulated annealing algorithm[2], the ant colony algorithm[3], the particle swarm optimization(PSO) algorithm[4]. Particularly among those algoritms, PSO algorithm, as a kind of intelligent evolutionary algorithm, has the advantages of few parameters and easy to implement.

When a dimension of the particle position exceeds the range $\left(-X_{\max },+X_{\max }\right)$ during the iteration, the upper position will be reset to $+X_{\max }$, and lowwer position will be reset to $-\mathrm{X}_{\max }$. This is the penalty strategy for particles position.

When a dimension of the particle velocity exceeds the range $\left(-\mathrm{V}_{\max },+\mathrm{V}_{\max }\right)$ during the iteration, the upper velocity will be reset to $+\mathrm{V}_{\max }$, and lowwer speed will be reset to $-\mathrm{V}_{\max }$ according to penalty strategy. This is the penalty strategy for particles speed.

But the performance of the particle swarm algorithm could been badly weakened by the viscous effect caused by the inherent defects within the reset strategy and the penalty strategy can solve the problem effectively.

In this study, a particle swarm optimization algorithm based on penalty strategy is proposed to solve the MMALSP.

\section{MMALSP}

It is unrealistic to establish the mode of mixed assembly line in closed-station for many products, such as cars, household electrical appliances. The model that created based on closed-station cannot describle actual demand in production properly. This paper establish the mode of mixed assembly line based on semi-closed station which the operator of workstation $\mathrm{k}$ can enter the workstation $\mathrm{k}+1$ to continue processing, and the operator of workstation $\mathrm{k}+1$ cannot enter the workstation $\mathrm{k}$ for processing or auxiliary processing in advance when the workstation $\mathrm{k}$ can not complete the product processing in fixed length of workstation.

Different sort of target might generate very different result. The optimization goal of the model is to minimize the overload time[5].

$A_{k i}$ is expressed as the assembly time of each product in Minimum Production Schedule(MPS) workstation K $(\mathrm{k}=1,2, \ldots, \mathrm{K} ; \mathrm{i}=1,2, \ldots, \mathrm{D})$ :

$$
\mathrm{A}_{\mathrm{ki}}=\left[\begin{array}{cccc}
\mathrm{T}_{11} & \mathrm{~T}_{12} & \cdots & \mathrm{T}_{1 \mathrm{D}} \\
\mathrm{T}_{21} & \mathrm{~T}_{22} & \cdots & \mathrm{T}_{2 \mathrm{D}} \\
\vdots & \vdots & \ddots & \vdots \\
\mathrm{T}_{\mathrm{K} 1} & \mathrm{~T}_{\mathrm{K} 2} & \cdots & \mathrm{T}_{\mathrm{KD}}
\end{array}\right]
$$

For station K, two kinds of situations may occur:

1. When assembly of the product $i$ is complete, the product $i+1$ has not entered the station, workers waiting at the starting point, this is idle situation.

2. Workers dose not complete their assembly tasks within the specified time in their own work, so that other workers will have to help them, this is overload situation.

For the station k: The operater waiting for the arrival of the product at the starting point of station $\mathrm{k}$ when each Minimum Production Schedule(MPS) begins. Start time can be expressed as follows:

$\mathrm{S}_{\mathrm{k} 1}=0, \mathrm{k}=1,2, \ldots, \mathrm{K}$; Where $\mathrm{k}$ represents the station $\mathrm{K}$, and 1 represents the $\mathrm{d}=1$ product of the station $\mathrm{K}$.

From the matrix $A_{k i}$ we can know that the processing time of the $\mathrm{d}(\mathrm{d}=1,2, \ldots, \mathrm{D})$ product at $\mathrm{k}$ station is $\mathrm{T}_{\mathrm{kd}}$, $\mathrm{k}=1,2, \ldots, \mathrm{k} ; \mathrm{d}=1,2, \ldots, \mathrm{D}$; Where $\mathrm{k}$ is the $\mathrm{k}$ station, $\mathrm{D}$ is the $\mathrm{D}$ product in the station. 
The end of the processing time of the $\mathrm{d}$ product in $\mathrm{k}$ station is expressed as:

$$
\mathrm{E}_{\mathrm{kd}}=\mathrm{S}_{\mathrm{kd}}+\mathrm{T}_{\mathrm{kd}}
$$

We assume that the rate of delivery of the product is fixed as the rhythm of the line C. Operators back to the assembly point immediately when the assembly of the D product is finished. Hence, here are the two expression of the processing start time of the $\mathrm{d}+1$ product in sequence of production:

1 When the assembly task of produnct $\mathrm{d}$ in station $\mathrm{k}$ is finished ahead of schedule, that is, $\mathrm{E}_{\mathrm{kd}} \leq \mathrm{C}$, the operator will wait at the beginning of the station, the station is in idle state, the start time of the $d+1$ product can be expressed as

$$
\mathrm{S}_{(\mathrm{k}, \mathrm{d}+1)}=0
$$

2 When the assembly task of produnct $\mathrm{d}$ in station $\mathrm{K}$ is not finished ahead of schedule, that is, $\mathrm{E}_{\mathrm{kd}}>\mathrm{C}$, the operator need to continue assembling in the station, the station is in overload state, the start time of the $\mathrm{d}+1$ product can be expressed as $\mathrm{S}_{(\mathrm{k}}$, $\mathrm{d}+1)=\mathrm{E}_{\mathrm{kd}}-\mathrm{C}$;

To summarize: $\mathrm{S}_{(\mathrm{k}, \mathrm{d}+1)}=\max \left\{0, \mathrm{E}_{\mathrm{kd}}-\mathrm{C}\right\}$

The idle time of product $\mathrm{d}$ in station $\mathrm{k}$ is:

$$
\operatorname{Idle}_{k \mathrm{~d}}=\max \left\{0, \mathrm{C}-\mathrm{E}_{\mathrm{kd}}\right\}
$$

The over time of product $\mathrm{d}$ in station $\mathrm{k}$ is:

$$
\operatorname{Over}_{\mathrm{kd}}=\max \left\{0, \mathrm{E}_{\mathrm{kd}}-\mathrm{C}\right\}
$$
is:

The sum of the idle time and the overload time of all station

$$
\begin{aligned}
& \mathrm{T}=\sum_{\mathrm{k}=1 \mathrm{~d}=1}^{\mathrm{K}} \mathrm{D}\left(\operatorname{Idel}_{\mathrm{kd}}+\text { Over }_{\mathrm{kd}}\right) \\
& \text { s.t. } \\
& \mathrm{S}_{\mathrm{k} 1}=0 ; \\
& \mathrm{k}=1,2, \ldots, \mathrm{K} ; \\
& \mathrm{d}=1,2, \ldots, \mathrm{D} ;
\end{aligned}
$$

\section{ALGORITHM DESIGN OF THE MODEL}

\section{A. Particle Swarm Optimization Algorithm}

PSO Algorithm, as a kind of swarm intelligence algorithm, is derived from the concept of population and evolution in evolutionary algorithms, which comes from artificial life and theory of evolutionary algorithms[6].

The number of the particle is $\mathrm{i}=(1,2, \ldots, \mathrm{N})$, the dimension of the feasible region of the solution is the dimension of the position or velocity for particle $i$, which is $d=(1,2, \ldots, D)$, and the position and velocity of particles are expressed as:

$$
\begin{aligned}
& X_{i}=\left(X_{i 1}+X_{i 2}+, \ldots,+X_{i D}\right)^{T} \\
& V_{i}=\left(V_{i 1}+V_{i 2}+, \ldots,+V_{i D}\right)^{T}
\end{aligned}
$$

PSO algorithm starts the iteration process when the particle swarm is initialized. The particle $\mathrm{i}$ updates its own properties based on two "optimal value" in each iteration. The first "optimal value" is the optimal solution found by the particle $\mathrm{i}$ itself, called Pbest, which can be regarded as the experience of the particle itself; Gbest is another optimal value, as the optimization experience of particle swarm, which which is the optimal solution of the whole particle swarm. The following is the update formula of particle velocity and position:

$$
\begin{gathered}
\mathrm{V}_{\mathrm{iD}}^{\mathrm{k}+1}=\omega * \mathrm{~V}_{\mathrm{iD}}^{\mathrm{k}} \\
+\mathrm{C} 1 * \operatorname{rand} *\left(\text { Pbest }_{\mathrm{iD}}^{\mathrm{k}}-\mathrm{X}_{\mathrm{iD}}^{\mathrm{k}}\right) \\
+\mathrm{C} 2 * \operatorname{rand} *\left(\text { Gbest }_{\mathrm{iD}}^{\mathrm{k}}-\mathrm{X}_{\mathrm{iD}}^{\mathrm{k}}\right) \\
\mathrm{X}_{\mathrm{iD}}^{\mathrm{k}+1}=\mathrm{X}_{\mathrm{iD}}^{\mathrm{k}}+\mathrm{V}_{\mathrm{iD}}^{\mathrm{k}}
\end{gathered}
$$

Here, $\omega$ is inertia weight, and $\mathrm{C} 1, \mathrm{C} 2$ are learning factors. We make $\mathrm{C} 1=\mathrm{C} 2=2$; Rand is a random number for the $(0,1)$, and the velocity of the particle $\mathrm{i}$ with $\mathrm{D}$ dimension in $\mathrm{k}$ iteration is $V_{\mathrm{id}}^{\mathrm{k}}$.

The speed and position are constantly updated according to the formula (3) and (4), until the times of maximum iteration or the accuracy of the solution is satisfied.

\section{B. PSO Based on Penalty Strategy}

\section{1) Reset Strategy}

Take the Rosenbrock Problem with solution space $(-2.048,2.048)^{\mathrm{T}}$ as an example:

In the $\mathrm{k}$ iteration, when the velocity of the particle $\mathrm{i}$ in the $\mathrm{h}$ and $\mathrm{h}+1(0<\mathrm{h}<\mathrm{d}-1)$ dimension reach the velocity boundary, the velocity of the particle is expressed as:

$$
\mathrm{V}_{\mathrm{ik}}\left(\mathrm{V}_{1}, \mathrm{~V}_{2}, \ldots, 2.05,-2.05, \ldots, \mathrm{V}_{\mathrm{d}}\right) \text {; }
$$

In the formula, $2.5>2.048,-2.5<-2.048$, the particle velocity in the $\mathrm{h}$ dimension will be reset to the upper boundary of the velocity, and the particle velocity of the $\mathrm{h}+1$ dimension will be reset to the lower boundary of the velocity, according to the speed reset strategy, that is:

$$
\mathrm{V}_{\mathrm{ik}}\left(\mathrm{V}_{1}, \mathrm{~V}_{2}, \ldots, 2.048,-2.048, \ldots, \mathrm{V}_{\mathrm{d}}\right) \text {; }
$$

In the $\mathrm{k}+1$ iteration, the speed of each dimension is updated according to the velocity update formula. Velocity updating formula of particle $\mathrm{i}$ in the $\mathrm{h}$ dimension is described as:

$$
\begin{aligned}
\mathrm{V}_{\mathrm{iD}}^{\mathrm{k}+1} & =\omega * \mathrm{~V}_{\mathrm{iD}}^{\mathrm{k}} \\
& +\mathrm{C} 1 * \operatorname{rand} *\left(\mathrm{Pbest}_{\mathrm{iD}}^{\mathrm{k}}-\mathrm{X}_{\mathrm{iD}}^{\mathrm{k}}\right) \\
& +\mathrm{C} 2 * \operatorname{rand} *\left(\text { Gbest }_{\mathrm{iD}}^{\mathrm{k}}-\mathrm{X}_{\mathrm{iD}}^{\mathrm{k}}\right)
\end{aligned}
$$

The first part of the velocity update formula $\omega * V_{\mathrm{iD}}^{\mathrm{k}}$ is equal to $0.9 * \mathrm{~V}_{\max }$ in the $\mathrm{k}+1$ iteration. If the sum of the second and third parts is more than $0.1 * \mathrm{~V}_{\max }$ at the same time, then

$\mathrm{V}_{\mathrm{iD}}^{\mathrm{k}+1}>(0.9+0.1) \mathrm{V}_{\max }$, the velocity of the particle $\mathrm{i}$ with the $\mathrm{h}$ dimension will continue to be reset to $+\mathrm{V}_{\max }$ in the $\mathrm{k}+1$ iteration. In other words, the speed of the particle $i$ is not involved in the optimization due to defect of the reset stratergy. If the distance between the particles is larger at the beginning of iter- 
ation, the speed change caused by individual experience (the second part of formula) and group experience (the third part of formula) will be relatively large, so the probability that $t$ the $h$ dimension of particle $i$ to be excluded continuously in the optimization process is very high.

Similarly, the probability that particle $\mathrm{i}$ with $\mathrm{h}+1$ dimension and particle $\mathrm{i}$ with $\mathrm{h}$ dimension are excluded from the optimization process is the same.

The exclusion and locking of optimization for particle caused by reset strategy are called as the viscous effect of the boundary.

\section{2) Penalty Strategy}

When a dimension of the particle velocity exceeds the range $\left(-\mathrm{V}_{\max },+\mathrm{V}_{\max }\right)$, the upper velocity will be reset to $\mathrm{P} *+\mathrm{V}_{\max }$ and lowwer speed will be reset to $\mathrm{P} *-\mathrm{V}_{\max }$ according to penalty strategy. This is the penalty strategy for particles speed.

When a dimension of the particle position exceeds the range $\left(-X_{\max },+X_{\max }\right)$, the upper position will be reset to $\mathrm{P} *+\mathrm{X}_{\max }$ and lowwer position will be reset to $\mathrm{P} *-\mathrm{X}_{\max }$. This is the penalty strategy for particles position

Where $\mathrm{P}(0.8<\mathrm{P}<1)$ is a penalty factor, the velocity or position which exceeds the range and needs to be reseted should multiplied by the penalty factor, so that the particle velocity and position can be left out of the boundary, and eliminating the viscous effect caused by velocity boundary and the solution space boundary.

\section{Relationship Between Sequence and Particle}

The mixed model assembly line sequencing problem is a discrete combinatorial optimization problem, and the standard particle swarm optimization algorithm can only solve the problem of continuous space. In order to apply the particle swarm optimization algorithm to the mixed model assembly line sequecing problem, relationship between sequence and particla should be explained.

1) The position of particle: $\mathrm{Xi}$, as the position of the particle $\mathrm{i}$, represents the production sequence of mixed flow assembly line.

2) The velocity of particle: The particle's velocity is automatically generated according to the size of the solution space, and is updated automatically according to the particle update formula in each iteration process.

3) Fitness of particle: The optimization goal of the model is to minimize the overload time.

\section{Coding and Decoding}

Coding design of PSO is the basis of the whole algorithm. First, the rationality of the allocation scheme for each particle, as well as whether it covers the whole solution space, needs to be considered. Second, we should consider whether the proposed coding scheme can be used to update the particle in the algorithm. If the distribution scheme of particle is not reasonable, it may affect the quality of the solution; otherwise, it could not guarantee the effectiveness of the algorithm.
Random number identification[7] is used to encode, and mapping between the particle swarm optimization algorithm and the mixed model assembly line sequencing problem is established. The random number code can be applied to the particle update formula, so that the particle swarm optimization algorithm can solve the discrete problem as mixed model assembly line sequencing problem.

Decode: The format of solution is a sequence of production, and the decoding process only needs to output the optimal location information after output iterative, and convert it to a sequence.

\section{EXAMPLE}

The mixed model assembly line is used to an assembly workshop which has 6 workstations and 4 products by assembled hybrid. MPS has 5A, 4B, 3C, 2D, a total of 14 product[8].

TABLE I. OPERATING TIME

\begin{tabular}{llllll}
\hline \multirow{2}{*}{ Workstation } & \multirow{2}{*}{$\begin{array}{l}\text { Station } \\
\text { length }\end{array}$} & \multicolumn{4}{c}{ Production time of different products } \\
\cline { 3 - 6 } & A & B & C & D \\
\hline 1 & 60 & 58 & 45 & 48 & 55 \\
2 & 60 & 45 & 64 & 47 & 60 \\
3 & 50 & 48 & 42 & 0 & 56 \\
4 & 50 & 50 & 0 & 55 & 60 \\
5 & 55 & 57 & 55 & 45 & 59 \\
6 & 55 & 0 & 51 & 60 & 58 \\
\hline
\end{tabular}

In order to verify the improvement of performance that penalty strategy could conduct, this paper compares the results while to solve the case above by using the PSO based on the reset strategy and Penalty-PSO(P_PSO) based on the penalty strategy.

The parameters of PSO algorithm are described as:

$\mathrm{C} 1=\mathrm{C} 2=1.5, \omega \max =1 ; \omega \min =0.4 ; \mathrm{K}=1000 ; \mathrm{N}=40$;

The parameters of $\mathrm{P} \_\mathrm{PSO}$ algorithm are described as:

$\mathrm{C} 1=\mathrm{C} 2=1.5 ; \omega \max =1 ; \omega \min =0.4 ; \mathrm{K}=1000 ; \mathrm{N}=40 ; \mathrm{P}=0.9$;

The average value, maximum value and minimum value are collected in the following table, after two algorithms run for 50 times

TABLE II. OPTIMIZATION RESULTS

\begin{tabular}{|l|l|l|l|}
\hline $\begin{array}{l}\text { Algorithm } \\
\text { type }\end{array}$ & $\begin{array}{l}\text { Minimum } \\
\text { value }\end{array}$ & $\begin{array}{l}\text { Maximum } \\
\text { value }\end{array}$ & $\begin{array}{l}\text { Average } \\
\text { value }\end{array}$ \\
\hline PSO & 132 & 176 & 154.5400 \\
\hline P-PSO & 131 & 170 & 151.0400 \\
\hline
\end{tabular}

The data in TABLE II shows that the penalty strategy can improve the performance of particle swarm algorithm but not markedly enough. In order to verify the advantage of penalty strategy, it is applied to the hybrid particle swarm optimization algorithm(SA_PSO) [9] for solving the Rosenbrock problem. After two algorithms run for 50 times, the distribution structure of solutions is obtained.

TABLE III. OPTIMIZATION RESULT

\begin{tabular}{|l|l|l|l|l|}
\hline $\begin{array}{l}\text { Algorithm } \\
\text { type }\end{array}$ & $\mathbf{( 1 , 1 , \ldots , 1 , 1 )}$ & $\mathbf{( 1 , 1 , \ldots , 0 , 0 )}$ & $\mathbf{( 0 , 0 , \ldots , 0 , 0 )}$ & $\begin{array}{l}\text { Reach } \\
\text { boundary }\end{array}$ \\
\hline SA_PSO & 17 & 8 & 0 & 25 \\
\hline P_SA_PSO & 34 & 10 & 6 & 0 \\
\hline
\end{tabular}


The parameters of SA PSO algorithm are described as:

$\mathrm{C} 1=\mathrm{C} 2=2.0 ;=0.9 ; \mathrm{K}=1600 ; \mathrm{N}=40 ; \mathrm{D}=10 ; \mathrm{a}=1.5$; initial temperature $\mathrm{T}=10000$; cooling rate $\lambda=0.99$;

The parameters of P_SA_PSO algorithm are described as: $\mathrm{C} 1=\mathrm{C} 2=2.0 ;=0.9 ; \mathrm{K}=1600 ; \mathrm{N}=40 ; \mathrm{D}=10 ; \mathrm{a}=1.5$; initial temperature $\mathrm{T}=10000[10]$; cooling rate $\lambda=0.99 ; \mathrm{P}=0.9$;

The hybrid particle swarm optimization algorithm based on reset strategy obtains 17 optimal solutions, and the hybrid particle swarm optimization algorithm based on penalty strategy gets 34 optimal solutions. Although hybrid particle swarm optimization algorithm can jump out of local optimal solution in a certain probability, the performance of the algorithm is greatly weakened by the viscous effect. And the penalty strategy can improve the performance of the algorithm by blocking the viscous effect.

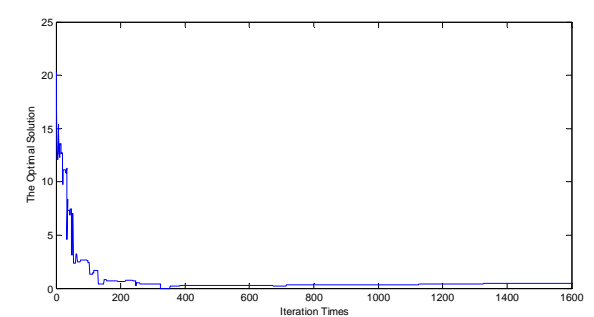

FIGURE I. CONVERGENCE OF PSO ALGORITHM

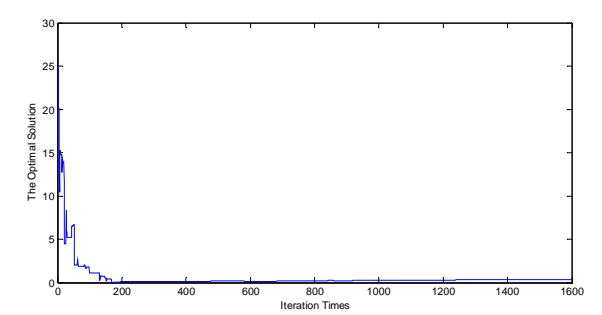

FIGURE II. CONVERGENCE OF P_PSO ALGORITHM

Figure II shows that Compared to the Standard SA PSO Algorithm, the P SA PSO Algorithm based on Penalty Strategy converges as quickly as the original one and keep good performance at the same time.

\section{CONCLUSION}

This paper propose a method based on penalty strategy to solve the mixed model assembly line sequencing problem in the semi-closed-station, A mathematical model is established to minimize the overload time in the paper, The optimization result verified the penalty strategy is more prominent than reset strategy. However, the MMALSP has a lot of optimization objectives, such as consumption rate of equalization which is the most important parts valued by TOYOTA Production System, and have not been considered yet. When there are multiple optimization objectives of mixed model assembly line sequencing problem, we need to further study mixed model assembly line sequecing problem with various goals, the sensitivity analysis about parameters and the penalty factor of PSO are still blank.

\section{ACKNOWLEDGMENT}

This work was supported by the Talent Training Fund of KunMing university of science and technology(No.KKSY201401007).

\section{REFERENCES}

[1] Jiang Yan,Li Xiangfeng,Zuo Dunwen,Jiao Guangming and Xue Shanliang, "Mixed-model assembly line optimization design based on improved Genetic Algorithm,"China Mechanical Engineering., vol. 21, pp. 2322-2328, Oct. 2010.

[2] Liu Zhaohui,Wang Chao, "Study on production sequencing of Mixed-model assembly line in JIT production mode based on simulated Annealing Algorithm,'Enterprise Logistics, vol.27, pp. 169-1711, 2008.

[3] Xue Qinwei,Lan Xiuju and Chen Chengpin, “Application of Ant Colony Algorithm to sequencing Mixed-model on Assembly lines,'Light Industry Machinery, vol.28, pp 107-112.Oct.2010

[4] Zhen Yongqian and Wang Yongsheng, "An Immunity Particle Swarm Sequencing Algorithm for Mixed-model assembly lines,'Industrial Engineering and Management, vol.16, pp.16-27,Aug.2011

[5] Huang Gang,Shao Xinyu and Rao Yunqing, "Study on multiple objects optimization of mixed model assembly sequencing problem,", J. Huazhong Univ. of Sci \& Tech.vol.35, pp. 84-86.Oct.2007

[6] Yang Wei and Li Qiqiang, "Particle Swarm Optimization Literature review," Enginnering Science, vol.6, pp. 87-94.May.2004

[7] BEAN J.C, "Genetic Algorithm and Random Keys for Sequencing and Optimization," ORAS Journal on Computing,1994, pp.154-160.

[8] Weng Yaowei,Lu Jiansha and Deng Wei, "Tabu particle swarm optimization for sequencing problems in mixed-model assembly lines,"Journal of Mechanical \& Electrical Engineering, vol.30, pp.430-434.

[9] Liu Qiong,Liu Weiqi and Zhang Chaoyong, "Hybrid GA-PSO algorithm for sequencing multi-objective mixed-model assembly lines,'J. Huazhong Univ. of Sci \& Tech., vol. 39, pp. 1-5, Oct. 2011.

[10] Chen Huagen,Wu Jiansheng,Wang Jialin and Chen Bing, "Mechanism study of simulated annealing algorithm,"JOURNAL OF TONGJI UNIVERSITY, vol.32, pp. 802-805.Jun.2004 